\title{
AN UNUSUAL SMALL BOWEL OBSTRUCTION (ABDOMINAL COCOON): A CASE REPORT
}

\author{
Invulgar obstrução intestino delgado (casulo abdominal): relato de caso
}

Seyed Ziaeddin RASIHASHEMI' ${ }^{1}$, Ali RAMOUZ ${ }^{2}$, Faeghe EBRAHIMI ${ }^{2}$

From the ${ }^{1}$ Department of Cardiothoracic Surgery and ${ }^{2}$ Medicine Faculty \& Student Research Committee, Tabriz University of Medical Sciences, Tabriz, Iran

\section{Correspondence:}

Ali Ramouz:

E-mail: Ali.ramouz@gmail.com

Financial source: none

Conflicts of interest: none

Received for publication: 13/08/2012

Accepted for publication: 16/04/2013

INTRODUCTION

A bdominal cocoon is a rare disease which causes small-bowel obstruction that is characterized by a thick, fibrotic and cocoon-like membrane encapsulating total or partially the small bowel $1^{1,2,3}$. Its etiology remains unknown ${ }^{4,5}$. Surgical management is the treatment of choice $^{1}$. In this report, it is described a young patient with abdominal cocoon who presented clinical signs and paraclinical findings of intestinal obstruction.

\section{CASE REPORT}

In July 2010 a 25 year-old man was admitted with 2-month history of intermittent colicky abdominal pain and bilious vomiting and abdominal distension. He also complained from chronic constipation, anorexia and 14 $\mathrm{kg}$ weight loss during the previous two months. He had no surgical or other medical history except using of a body building supplement drugs which contain creatin.

On physical examination he was anxious. Vital signs were normal (blood pressure 110/75, pulse rate $85 /$ min, temperature $37.3^{\circ} \mathrm{C}$ ). Abdominal distention with hyperactive bowel sounds and mild tenderness in the whole of the abdomen especially in left upper quadrant were detected at physical examination. There were no abdominal scars, palpable abdominal mass or organomegaly. Digital rectal examination was normal. Laboratory blood analysis ascertained a total leukocyte count $8500 \mathrm{cell} / \mathrm{ml}$, hemoglobin $16 \mathrm{mg} / \mathrm{dl}$, normal serum chemistry and normal urine analysis. Up right plain abdominal X-ray showed multiple air-fluid levels without free gas under the diaphragm. The barium $X$-ray showed jejunal and ileal loops dilatation with the contrast medium passing slowly (Figure 1 ). Contrastenhanced abdominal computed tomography showed small bowel loops and dilatation (Figure 2).

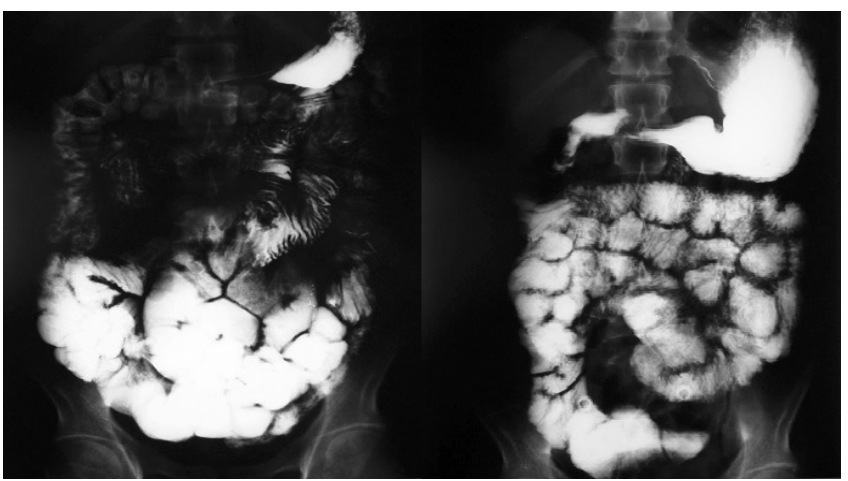

FIGURE 1 - Barium x-ray showing a cauliflower appearance in the lower abdomen and pelvis

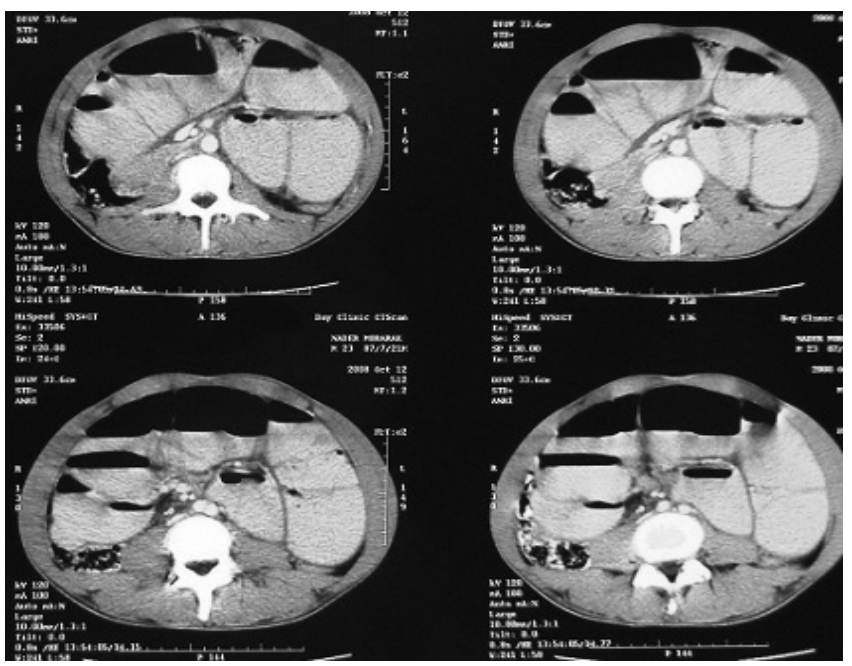

FIGURE 2 - Contrast-enhanced abdomen CT demonstrates small bowel dilatation with air-fluid level

Due to signs of mechanical small bowel obstruction an emergency laparotomy was performed through a midline incision. During surgery the small bowel dilatation was observed; its mesentery was edematous and the whole small bowel covered by a dense whitish 
membrane which gave the appearance of a cocoon (Figure 3). Careful sharp and blunt dissection with excision of the membrane enveloping the small bowel was performed and the whole small intestine was freed and followed from duodenojejunal angle to ileocecal junction. The histopathology of the peeled off membrane revealed a chronic non-specific inflammatory reaction with proliferation of fibroconnective tissue.

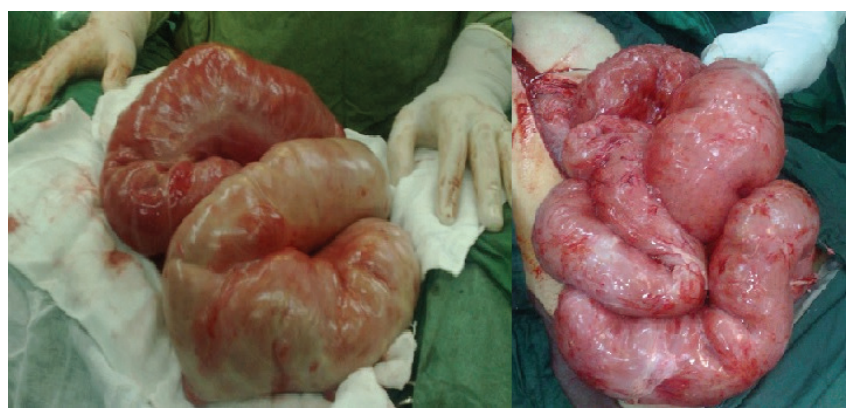

FIGURE 3 - Intraoperative photograph showing small intestine encapsulated in white, thickened cocoon-like membrane

The patient was discharged from the hospital on the $8^{\text {th }}$ postoperative day. After 24 months regular follow-up he was in satisfactory condition and the abdominal plain showed normal appearance.

\section{DISCUSSION}

Sclerosing encapsulating peritonitis can be classified as idiopathic and secondary. The idiopathic class or abdominal cocoon was first described by Foo et al in $1978^{6}$. The idiopathic type primarily affects young females from tropical and subtropical countries ${ }^{1}$.The cause of this rare condition is unknown $n^{2,3}$ although a number of hypotheses have been mentioned ${ }^{4,7}$. Abdominal cocoon is characterized by a thick shiny fibrotic membrane, with total or partial encasement of the small intestine ${ }^{5}$.

In clinical presentation, abdominal cocoon is presented by recurrent attacks of acute or subacute small bowel obstruction, nausea, weight loss and anorexia and sometimes with palpable abdominal mass. Most patients are diagnosed incidentally at laparotomy and preoperative diagnosis requires a high index of clinical suspicion ${ }^{8}$.

This patient had used some supplements for body buildings such as creatin for four years. No reference was found in the literature any association between medication given and abdominal cocoon.

WBC count, C-reactive protein level, hypoalbuminemia and anemia are common findings in SPE cases but no significant sign was observed in this case $^{2}$. Imaging has an important role in the diagnosis of abdominal ${ }^{9}$. Barium X-ray and contrast CT are useful for the diagnosis of abdominal cocoon preoperatively ${ }^{5}$. Dilated bowel loops with multiple air-fluid level may be shown in conventional abdominal X-ray but they are nonspecific ${ }^{5,7}$. The classic findings of abdominal CT consist of small bowel loops congregation in the center of abdomen with a non-enhancement fibrous membrane surrounding the bowl loops that is best visualized on computed axial tomography scan sch, $^{3,10}$. Surgical dissection and excision of the membrane and adhesionlysis remain the cornerstone in the treatment of abdominal cocoon ${ }^{2,5}$. In reported case with an insignificant history, a dilated small bowel with an edematous mesentery and a dense whitish membrane coverage on bowel observed in operation which advised idiopathic sclerosing peritonitis

Because of increasing morbidity and mortality following bowel resection, only if it is nonviable, resection of the bowel is indicated ${ }^{7}$. In this case an emergency laparotomy was performed and an edematous mesentery covered by a dense whitish membrane wasd observed and incised carefully, separated from the intestinal serosa by sharp and blunt dissection.

In general, prognosis of abdominal cocoon after surgery is satisfactory and excision of the thick membrane and release of the small intestine leads to complete recovery.

In conclusion sclerosing encapsulating peritonitis is not common and definite preoperative diagnosis is difficult. The recurrent episodes of small bowel obstruction combined with relevant preoperative findings at imaging studies and lack of other causes can facilitate preoperative diagnosis of abdominal cocoon.

\section{REFERENCES}

1. Serafimidis C, Katsarolis I, Vernadakis S, Rallis G, Giannopoulos G, Legakis N, Peros G: Idiopathic sclerosing encapsulating peritonitis(or abdominal cocoon). BMC surgery J 2006, 6:3.

2. Tombak MC, Apaydin FD, Colak T, Duce MN, Balci Y, Yazici M, Kara E: An unusual cause of intestinal obstruction: Abdominal Cocoon. AJR Am J Roentgenol 2010; 194:W176-W178.

3. Xu p, Chen LH, Li YM: Idiopathic scleroting encapsulating peritonitis (or abdominal cocoon): A report of 5 Cases. World J Gastroenterol 2007; 13(26): 3649-3651.

4. Tannoury JN, Abboud BN: Idiopathic sclerosing encapsulating peritonitis: Abdominal cocoon. World J Gastroenterol 2012; 18(17).

5. Wei B, Wei HB, Guo WP, Zheng ZH, Huang Y, Hu BG, Huang JL. Diagnosis and treatment of abdominal cocoon: a report of 24 cases. Am J Surg. 2009 Sep;198(3):348-53

6. Foo KT, Ng KC, Rauff A, Foong WC, Sinniah R: Unusual small intestinal obstruction in adolescent girls: the abdominal cocoon. Br J Surg 1978, 65:427-430.

7. Devay AO, Gomceli I, Korukluoglu B, Kusdemir A: An unusual and difficult diagnosis of intestinal obstruction: The abdominal cocoon. Case report and review of the literature. World J Emerg Surg 2006, 1:8.

8. Kawaguchi $Y$, Kawanishi H, Mujais S, Topley N, Oreopoulos DG: Encapsulating peritoneal sclerosis: definition, etiology, diagnosis, and treatment. International society for peritoneal dialysis ad hoc committee on ultradiltration management in peritoneal dialysis: Perit Dial Int. 2000, 20 supple 4: 543-55.

9. Hur j, Kim KW, Park MS, Yu JS: Abdominal cocoon preoperative diagnostic clues from radiologic imaging with pathologic correlation. AJR Am J Roentgenol 2004, 182:639-641.

10. Wig JD, Gupta SK: Computed tomography in abdominal cocoon. J Clin Gastreoenterol 1998, 26:156-157. 